University of Wollongong

Research Online

Faculty of Engineering and Information

Faculty of Engineering and Information

Sciences - Papers: Part A

Sciences

$1-1-2016$

\title{
Lubrication characterisation analysis of stainless steel foil during micro
} rolling

Haibo Xie

University of Wollongong, xie@uow.edu.au

Kenichi Manabe

Tokyo Metropolitan University

Tsuyoshi Furushima

Tokyo Metropolitan University, tsuyoshi@uow.edu.au

Kazuo Tada

Tokyo Metropolitan University

Zhengyi Jiang

University of Wollongong, jiang@uow.edu.au

Follow this and additional works at: https://ro.uow.edu.au/eispapers

Part of the Engineering Commons, and the Science and Technology Studies Commons

Research Online is the open access institutional repository for the University of Wollongong. For further information contact the UOW Library: research-pubs@uow.edu.au 


\title{
Lubrication characterisation analysis of stainless steel foil during micro rolling
}

\begin{abstract}
Physical parameters, such as microscopic and roughness, play important roles in microforming process due to an increasing ratio of surface to volume of the deformed material. The study on lubrication characterisation in microforming is getting more attractive to researchers because traditional models are not reliable in this scaled down process. In this study, the micro rolling deformation characterisation has been investigated on SUS 304 stainless steel considering lubricant effect and feature size effect. The foil thickness plays an important role in the tribological features of micro rolling. The evolutions of both oil film thickness and foil surface are analysed accordingly. All the results have been verified experimentally via the new developed $2-\mathrm{Hi}$ desktop micro rolling mills.
\end{abstract}

\section{Keywords}

micro, during, foil, steel, stainless, analysis, rolling, characterisation, lubrication

Disciplines

Engineering | Science and Technology Studies

\section{Publication Details}

Xie, H., Manabe, K., Furushima, T., Tada, K. \& Jiang, Z. (2016). Lubrication characterisation analysis of stainless steel foil during micro rolling. International Journal of Advanced Manufacturing Technology, 82 (1), 65-73. 


\title{
Lubrication characterisation analysis of stainless steel foil during micro rolling
}

\author{
Haibo Xie ${ }^{\text {a,b }}$, Ken-ichi Manabe ${ }^{a}$, Tsuyoshi Furushima ${ }^{a}$, Kazuo Tada ${ }^{a}$, Zhengyi Jiang ${ }^{b}$ \\ ${ }^{a}$ Department of Mechanical Engineering, Tokyo Metropolitan University, 1-1 Minami-Osawa, Hachioji, Tokyo 192-0397, Japan \\ ${ }^{b}$ School of Mechanical, Materials and Mechatronic Engineering, University of Wollongong, Northfield Ave, Wollongong, NSW 2500, \\ Australia
}

\begin{abstract}
Physical parameters, such as microscopic and roughness, play important roles in micro forming process due to an increasing ratio of surface to volume of the deformed material. The study on lubrication characterisation in micro forming is getting more attractive for researchers because traditional models are not reliable in this scaled down process. In this study, the micro rolling deformation characterisation has been investigated on SUS 304 stainless steel considering lubricant effect and feature size effect. The foil thickness plays an important role in the tribological features of micro rolling. The evolutions of both oil film thickness and foil surface are analysed accordingly. All the results have been verified experimentally via the new developed 2-Hi desktop micro rolling mills.
\end{abstract}

Keywords: Lubrication characterization; Foil rolling; Oil film thickness; Surface roughness

\section{Introduction}

Due to the trend of miniaturization on electrical equipment, medical devices, and energy industries, etc., the demand in micro metallic foil has been extremely increasing, especially in stainless steel foil because of its excellent corrosion resistances and high strengths. Metallic foil is mostly obtained by multi-pass rolling process through cluster multi-roll mills, such as Sendzimir mill, 12-high cluster type etc. This kind of cluster rolling mill is complex and also difficult to operate and maintain. Surface quality is a major consideration in metal forming processes. However, the knowledge and technique developed in traditional metal rolling cannot be directly applied to the micro foil rolling process due to the so-called size effects which further affect the performance of microforming system and product quality in terms of dimensional accuracy, surface finish and mechanical properties. Lubricant, being indispensable in the cold rolling, provides necessary cooling of the rolled material, reduces wear of both the rolled material and rolls, and lowers the friction during rolling[1, 2]. Combining the cooling capacity of water with the lubricating property of oil, an oil-in-water $(\mathrm{O} / \mathrm{W})$ emulsion is normally applied as the lubricant in cold rolling. The lubrication film is the layer of fluid (emulsion or lubricating oil) inside the rolling contact zone. Compared to the amplitude of the surface roughness, the thickness of the lubrication film in the contact zone influences the lubricating regime and surface quality. An oil film layer may be built by the surface roughness that entrains a significant amount of emulsion between the rolled materials and rolls. Successive pass usually leads to successively lower pass thickness reduction because of the work hardening of the rolled material in the previous passes [3]. Particular interest has been arisen in modelling friction and surface roughness, both to improve product quality, mill productivity and reduce energy consumption. The lubrication characterisation analysis could be principally of importance in metal forming, especially in foil rolling. Numerical and analytical modelling of cold rolling provides ideal processing conditions which minimize the excessive metallic contact between the rolled materials and rolls.

Traditional cold rolling theories with an assumption that contact arc remains a circular with enlarged radius and includes one neutral point fail in foil rolling process due to significant elastic deformation of the roll. Some related researches have been conducted on this issue. Fleck and Johnson [4, 5] suggested that the roll deformed to a non-circular profile and a neutral region of no-slip existed in the roll bite for finite reductions of the strip, and plastic reduction occurred near the rolling entry and rolling exit zones. For scale-down size effect, Vollertsen and $\mathrm{Hu}$ [6] analysed tribological size effects in sheet metal forming. An open and closed pockets theory has been proposed to analyse this scaled down effect on material surface deformation behaviour in micro forming process [7]. Tribological analysis is very important in cold rolling process. Le and Sutcliffe [1, 2] applied a tribological model for the mixed lubrication which indicated that the friction coefficient on the asperity contact was related to oil film thickness. The oil film thickness could be estimated by the measured surface brightness of cold rolled sheets [8]. The combined effect of friction and macroscopic deformation on asperity flattening was reported in Ref [9], and roll roughness and lubricant viscosity influence the loads [10]. Quantitative characterisation of the surface topography of cold rolled sheets could be identified [11]. Lubrication influences the deformation mode and mechanical properties of the final product. If the lubricant does not show the properties necessary to establish a hydrodynamic regime, the film will be broken and re-established and the process will become unstable. Predications of film thickness from the various models are showing that the film thickness depends on many factors, such as the rolling speed, oil properties, the inlet geometry, the yield stress, 
the strip thickness, the asperity geometry and the entry tension [12-16]. These work presented mathematical models based on the slab method built to analyse the lubrication during cold rolling of strip.

Oil film thickness influences the lubricate distribution and the friction characterisation during rolling. Prediction in the contact area between the rolled strip and rolls also requires detailed information of how the pressurized oil separates the strip and rolls. Therefore oil film thickness always plays a central role whichever the lubrication theory is. In this study, the rolling deformation characterisation of foil rolling in SUS304 stainless steel has been investigated on the $2-\mathrm{Hi}$ reversing micro rolling mill. The influences of the feature sizes on oil film thickness have been discussed in this high strength material with ranging thicknesses from $50 \mu \mathrm{m}$ to 100 $\mu \mathrm{m}$. The analysis of oil film thickness evolution, rolling force and surface topography and quality have also been conducted experimentally and analytically. Some variables of the process were studied, such as rolling speed, reduction to evaluate their influence on the pressure distribution, film thickness of the lubricant, and on the surface roughness of cold rolled foils as well.

\section{Experimental micro rolling mill and material used}

The research on multi-pass rolling deformation behaviour of SUS 304 stainless steel has been carried out on the 2-Hi reversing micro rolling mill which includes gear system, paralleled motor, gap adjustment device, micro rollers, shaft connection and control system as shown in Fig. 1. The rollers are driven by two separated motors and this rolling mill is featured with adjustable and flexible rolling speed ratio for up and down rollers. The initial thicknesses of SUS 304 stainless steel foil are $50 \mu \mathrm{m}$ and $100 \mu \mathrm{m}$ with the foil width of $15 \mathrm{~mm}$.

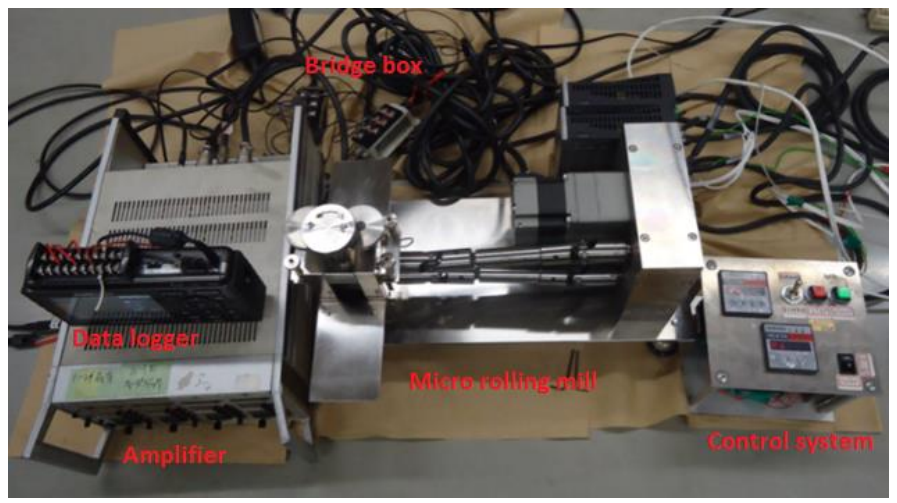

Fig. 1 Desk-top micro rolling mill with flexible speed ratio.

Table 1. Parameter conditions in experimental and analysis.

\begin{tabular}{cllll}
\hline \multirow{2}{*}{ Roll } & Work roll diameter $(\mathrm{mm})$ & Rolling speed $(\mathrm{rpm})$ & Roll Young's modulus $(\mathrm{GPa})$ & Passion ratio \\
\cline { 2 - 5 } & 27 & $0-100$ & 580 & 0.30 \\
\cline { 2 - 4 } & Entry foil thickness $(\mu \mathrm{m})$ & Reduction $(\%)$ & Young's modulus $(\mathrm{GPa})$ & Poisson ratio \\
Fubrication & 50 and 100 & $0-50$ & 210 & 0.30 \\
\hline
\end{tabular}

Table 1 lists parameters used in experimental and analytical models. The rolled foil is collected, measured and compared after each pass. It is very important to use flat samples, especially relevant to the thin foil to ensure the measurement accuracy. The roll and the rolled foil are degreased with acetone before rolling in each pass. After rolling, the samples are carefully cut, trimmed and stunk onto the smooth surface of one hard metal block for observation.

\section{Results and discussion}

\subsection{Oil lubrication in metal forming}

In the rolling deformation region, both oil and water phases are mixed and entrained into the contact zone. The lubrication features depend on not only the surface roughness but also other factors such as relative sliding, surface waviness, lubricant viscosity and thickness reduction. These factors influence the hydrodynamic state in rolling lubrication as well $[8,12]$. Fig. 2 illustrates schematically the contact areas between the roll and the 
rolled material and separated areas by an oil film layer. Fig. 3 shows the micrograph of the rolled foil surface, in which there are many significant rolling traces along the rolling direction.
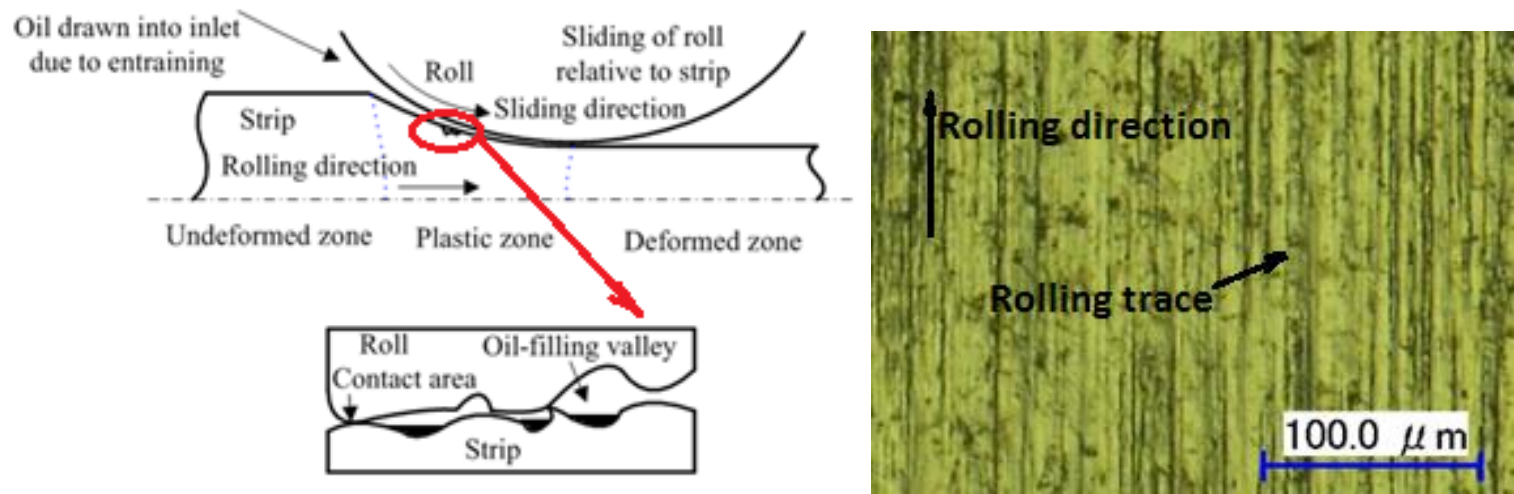

Fig. 2 Schematic of lubrication mechanisms in cold rolling and details of contact.

Fig. 3 Micrograph of the rolled foil surface

In the deformation regime, lubrication could be in a combined elato-plasto-hydrodynamic lubrication: elastic deformation in the roll, plastic deformation in the strip and hydodynamical behaviour in the lubrication oil when entrained by the motion of the strip and rolls. The pressure increases when the strip approaches the inlet zone before the contact zone by moving surfaces. The oil flow profile in the inlet zone is therefore a superposition of two flows: one is driven by the shearing force of the moving strip and roll surfaces, and the other is driven by the pressure build-up in the inlet zone [14]. A full film exists in the valleys of the surface as shown in Fig. 2 where rolling force and shear force are shared by asperities and the film. Rolling operations are normally run in mixed lubrication regime in which load capacity is generated by the hydrodynamic pressure of the lubricant in between the valley of the roughness asperity and the pressure at the contacting asperity surfaces.

\subsection{Mix lubricant analysis}

In the mixed lubrication regime, the roll imprints its roughness onto the steel foil surface and the pressure increases with decreasing oil film thickness. The entry oil film thickness is the oil film thickness at a point where the pressure reaches the yield stress of the rolled foil. After entering the inlet zone, oil droplets undergo a competition between the lateral force that drives them towards the focus plane, and the force of the flow itself that at some point returns and flows back out of the entry zone. The existence of the lateral force leads to migration of oil droplets across streamline that eventually bends towards the plane of zero velocity passes through this plane and returns [14]. Since the lubricant film has lower shear yield stress than the steel foil and rolls, shearing will occur in the film instead of in the rolled material. The lubrication film separates the surfaces and thereby prevents the mutual adhesion of the surfaces of the foil and rolls. Therefore serious surface defects in lubrication rolling could be avoidable which caused by adhesion, such as material transfer between the foil and rolls.

For foil rolling, elastic deformation of the rolls needs to be included to predict the shape of the bite region. Because the roll bite is very long compared with the foil thickness, the rolling load or reduction is particularly sensitive to friction. Coupled solutions including roll deformation should be conducted in foil rolling. As the rolling speed falls, the area of contact ratio raises which could lead to a rise in friction and a very large increase in rolling load as well. Because of the considerable roll flattening during rolling, the predicted load is very sensitive to the details of both the friction and elastic roll deformation models, so that the reasonable agreement needs to onfirm the accuracy of these models.

The mechanism of lubrication under asperity contacts has been termed micro plasto-mechanism of lubrication. Assumed that $\mathrm{x}$ axis is the rolling direction, an averaged Reynolds equation could be derived to present the variation in the rolling direction of the reduced hydrodynamic pressure $\mathrm{q}_{\mathrm{v}}$ of the lubricant as [16]:

$$
\frac{d\left(\gamma p_{v}\right)}{d x}=6 \eta_{0} \gamma\left(v_{\text {entry }}+v_{r}\right) \frac{h_{v}-h^{*}}{h_{v}^{3}\left(1+3 \psi_{c}{ }^{2} / h_{v}^{2}\right)}
$$

where, $h_{v}$ is the mean film thickness; $h^{*}$ the film thickness at the start of the roll bite, where the pressure gradient approaches zero; $\psi_{\mathrm{c}}{ }^{2}$ the local combined roughness of the foil and rolls; $\eta_{0}$ dynamic viscosity; $\gamma$ pressure-viscosity coefficient; $v_{\text {entry }}$ roll surface speed and $v_{r}$ entry speed of the foil.

When the asperities are crushed in the bite, the film thickness falls which leads to an increase in valley oil 
pressure. Accordingly, this increase in valley pressure prevents the asperity crushing process. Fleck et al $[4,5]$ showed that there existed slipping and sticking zones between roll and foil in foil rolling. The average shear stress $\tau$ is given by a weighted sum of the asperity and valley contributions and the shear stress in slipping regions can be estimated below $[17,18]$ :

$$
\begin{gathered}
\tau=A \tau_{a}+(1-A) \tau_{b} \\
\tau_{a}=\delta \mu_{a} p_{a} ; \delta=\frac{\theta}{\sqrt{\theta^{2}+\theta_{1}^{2}}} ; \tau_{b}=\eta \dot{\gamma}
\end{gathered}
$$

where, $\mathrm{A}$ is actual contact area ratio; $\mu_{a}$ Coulomb friction coefficient; $p_{a}$ the pressure on the asperity tops; $\theta$ the local roll slope and $\theta_{1}$ a representative roll slope in a slipping region; $\tau_{b}$ is the pressure on the asperity valley regions, which can be expresses using the Newtonian viscosity; the strain rate $\dot{\gamma}$ is estimated form the sliding speed and valley film thickness in the bite and the viscosity is taken at the pressure in the roll bite.

$$
p_{a}=\bar{p}+(1-A) Y \Delta ; p_{b}=\bar{p}-A Y \Delta
$$

where, $\mathrm{Y}$ is the plane strain yield stress of the rolled foil; $\Delta$ the effective hardness of the asperity; $\overline{\mathrm{p}}$ average pressure.

The contact area ratio, which is related to the average film thickness, is calculated on the basis of the asperity flattening theory by Chang and Wilson [19]:

$$
\frac{d A}{D x}=-\frac{2 x \delta}{M\left(2 l(1-A)+Y\left(\frac{A}{\left(\bar{p}-p_{v}\right) f_{1}(A)}-\frac{f_{2}}{f_{1}}\right)\right)}
$$

where, $\delta$ is thickness reduction; $f_{1}$ and $f_{2}$ are coefficients related to the contact area ratio. At a non-dimensional position, there is some contact between the foil asperities and rolls, leading to a non-zero area of contact ratio and a mean pressure $\bar{p}$ above the valley pressure $p_{b}$. At the end of the inlet region when the mean pressure has reached the yield stress $Y$, bulk deformation begins. Further asperity flattening occurs in the transition zone which is driven by the difference between the asperity and valley pressures. Equations (1) and (5) were solved by using the integrating method of Runge Kutta. The primary value of contact area ratio A was assumed to be 0.5 at the beginning of the solution. The required pressure for the rolling was supposed to be the yield stress of the material. This trial and error is continued until a convergence criterion is achieved. New values of lubricant pressure and contact area are also obtained from Eqs. (1-5).

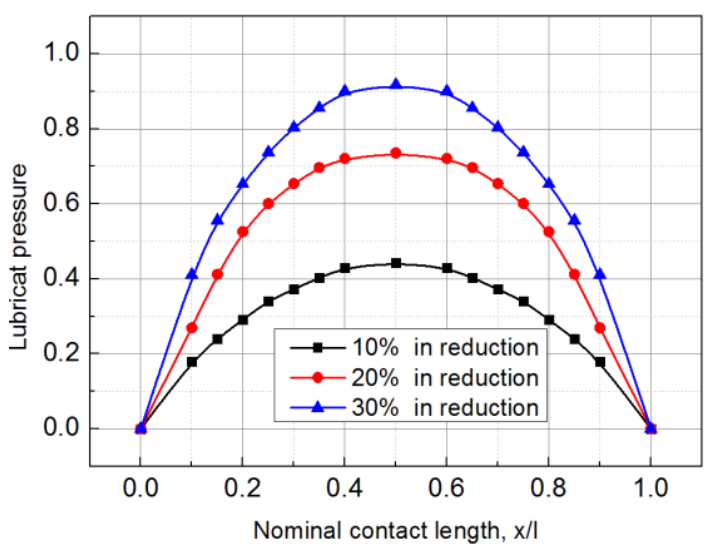

(a) Lubricant pressure

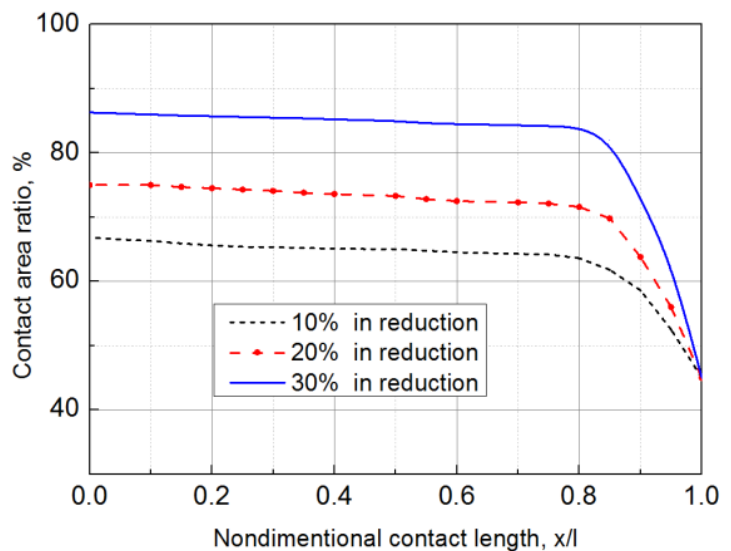

(b) Contact area ratio, $\%$

Fig. 4 The lubricant pressure and contact area ratio distribution under different rolling reduction.

The lubricant pressure and contact area ratio under different pass reduction are illustrated in Fig. 4. It can be seen that both the lubricant pressure and contact area ratio increase with the increasing pass reduction. Compared with lubricant pressure, contact area ratio increases slowly with the increasing pass reduction, especially at low reduction, while the influence of pas reduction on the lubricant pressure is more significant. In calculation modelling, the asperity slop is assumed to be constant and only asperity height crushing has been considered in rolling deformation.

\subsection{Oil film thickness}

In cold rolling with lubricant, the mechanism of film formation by emulsions at the entrance is complicated. Friction and the surface quality of the rolled strip are closely related to the amount of oil drawn into the bite. In order to investigate the oil film thickness in lubricant rolling, the direct oil-dropping method could be applied: 
dropping a known quality of oil on the strip surface, rolling the strip in the mill, and taking a digital photograph of nearly ellipse-shaped mark left on the strip after rolling. The length and width of this emulsion mark are measured, and the final thickness of the oil film between the roll and the rolled material can be obtained through the drop volume $\left(V_{d}\right)$ divided by the surface area of the mark $\left(A_{c}\right)$. The measured oil thickness is an average value. Because the volume of drop shrinks during rolling, the thickness of the film at the end of the mark could be somewhat lower. However this influence is small and the measured oil film thickness could be obtained by:

$$
h_{m}^{*}=\left(V_{d} / A_{c}\right) /(1-\delta)
$$

In theory, the oil film thickness could be determined by the lubricant rheological properties, the rolling speed and the roll geometry. Wilson and Walowit [12] calculated film thickness by applying an analytical solution of the Reynolds equation in the inlet zone and solving the continuity equation in the deformation regime. The simplified film thickness formula for smooth rolls and strip is shown below:

$$
\begin{aligned}
& h^{*}= \frac{3 \eta_{0} \gamma\left(v_{\text {entry }}+v_{r}\right) R^{\prime}}{L\left\{1-\exp \left[-\gamma\left(\sigma_{f m}-\sigma_{\text {entry }}\right)\right]\right\}} . \\
& R^{\prime}=R\left(1+\frac{16 \omega}{\pi E(H-h)}\right)
\end{aligned}
$$

A film thickness at the outlet of the contact zone can be calculated by

$$
h_{\text {out }}=h^{*} \frac{v_{\text {entry }}+v_{r}}{v_{\text {out }}+v_{r}}
$$

where, $\mathrm{h}^{*}$ is oil film thickness in the inlet zone; $\sigma_{\mathrm{fm}}$ average flow stress; $\sigma_{\text {entry }}$ tensile stress; $\omega$ : specific rolling force; $\mathrm{h}_{\text {out }}$ oil film thickness in outlet zone; $\mathrm{R}^{\prime}$ deformed roll diameter, $\mathrm{mm}$.

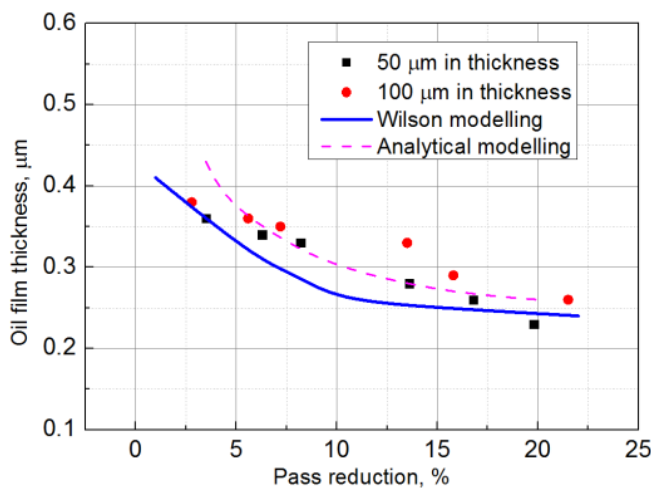

$(\mathrm{H}=100 \mu \mathrm{m}$ and $50 \mu \mathrm{m} ; v=25 \mathrm{rpm})$.

Fig. 5. Measured film thickness for emulsion and film thickness based on the Wilson model

Fig. 5 shows the comparison between the oil film thickness obtained from the Wilson model, analytical modelling and the measured value. All oil film thicknesses in experiment and calculation decrease with increasing pass thickness reduction. The results from the analytical modelling are closer to the experiment values. It can be seen that the calculated value is always smaller than the experiment measured value, and this is because the film formation by the entraining action and surface roughness effect have not yet been considered in the calculation model. Additionally the oil film thickness in $50 \mu \mathrm{m}$ thick foil is lower than that in thickness of $100 \mu \mathrm{m}$. With increasing miniaturization, more open lubricant pockets appear and less lubricant is kept in the micro tribological contact zone for thinner foil. Therefore the oil film thickness increases with increasing foil thickness.

The fraction of oil entrained into the contact zone significantly depends on the thickness reduction, it is reasonable that oil trapping between asperities of surface is subjected to viscous shearing, maintains its original viscosity and is ease to be entrained. A larger thickness reduction results in larger coalescence of the oil and the surface, so the oil thickness should be lower accordingly. There will be two reasons for this difference: the inlet zone and the roughness of the foil and rolls. The oil film becomes thicker with decreasing angle at the inlet of roll bite which had been identified in Ref. [17], but the effect will be insignificant because of its small inlet angle in foil rolling.

This curve obtained from the model in Eq. 7 is roughly in agreement with the trend of the measured oil 
thickness as shown in Fig. 5. A matching parameter $\mathrm{C}$ depending on the surface roughness could be introduced to reduce the difference between the measured value $h_{m}{ }^{*}$ and the calculated value $h_{c}$. The relationship can be expressed approximately in linear:

$$
h_{m}^{*}=C h_{c}
$$

The Wilson model to the oil film thickness can be applied through this matching parameter in considering the surface roughness effect. An accurate agreement between the calculation value and the measured value is obtained by inserting this matching $\mathrm{C}$, where $\mathrm{C}$ has a value of 1.05 for the smooth surfaces of $50 \mu \mathrm{m}$ and 1.12 for the rough surfaces of $100 \mu \mathrm{m}$ in this case.

Fig. 6 shows the measured oil film thickness versus the rolling speed in two different lubricating cases: emulsion and neat oil. It can be seen that both oil film thicknesses increase with increasing rolling speed slightly. The oil thickness in neat oil is higher than that in emulsion lubricant. Because viscosity decreases in emulsion lubrication, the film thickness decreases due to the increasing asperity contact area. When the asperity contact area increases, the pressure in asperity contact area increases accordingly and the film pressure decreases. This is testified that the oil film thickness would be slightly smaller than that in neat oil lubricant because of much lower viscosity in emulsions.

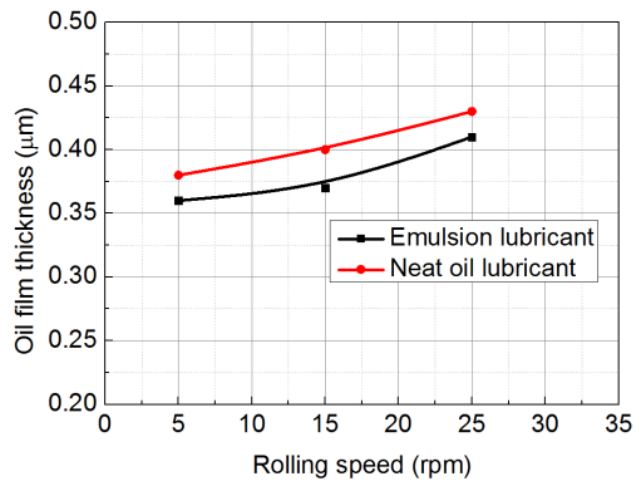

Fig. 6. Oil film thickness versus rolling speed in experiment $(\mathrm{H}=100 \mu \mathrm{m} ; \mathrm{r}=20 \%)$.

The rolling speed effect with wet lubricant indicates that some form of hydrodynamic lubrication is undergoing metal to metal contact. The rolling speed influences the viscosity of lubricant during rolling because the speed profile determines the oil drop movements. With increasing speed, more lubricant is carried to the interface filling the surface valleys, separating the surface peaks and establishing the mixed lubrication. The oil that was already on the strip surface is spread thinner by the elongation of the strip and the replenished oil makes up for the difference.

\subsection{Rolling parameters for various rolling conditions}

The effect of rolling conditions on the rolling force has been investigated during rolling experiments. Fig. 7 illustrates the rolling force changes with rolling time. Two pressure sensors are installed under both ends of the roll neck, respectively. The sensors are connected with the strain amplifier where the rolling force can be recorded by the data logger as shown in Fig. 1. It can be seen that the rolling force variation is great when biting the specimen in the rolling entrance due to rolling vibration, and the average rolling force is around $6.73 \mathrm{kN}$ for this experimental case. After that, the rolling force remains constant during rolling process.

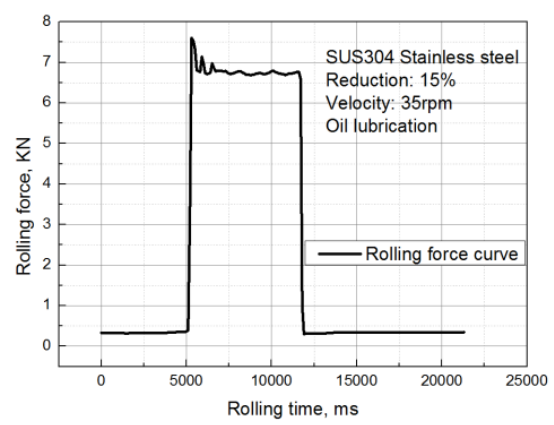

Fig. 7 Rolling force variation with rolling time (Rolling speed: 30 rpm; oil lubricant). 
Fig. 8 shows the effect of lubricating condition on the rolling force at various rolling speeds. It can be seen that the lubrications are significantly effective in reducing the rolling force at low rolling speed from $10 \mathrm{rpm}$ to $30 \mathrm{rpm}$. However, the effect of the rolling lubricating conditions is insignificant at high rolling speed of over 30 $\mathrm{rpm}$ because the hydrodynamic lubrication prevails against the boundary lubrication. The rolling force distinctly decreases due to the reduced friction from the rolling experiments where the lubricating condition changes from the boundary condition to the hydrodynamic condition. This is verified that the rolling force decreases quickly in low rolling speed zones.

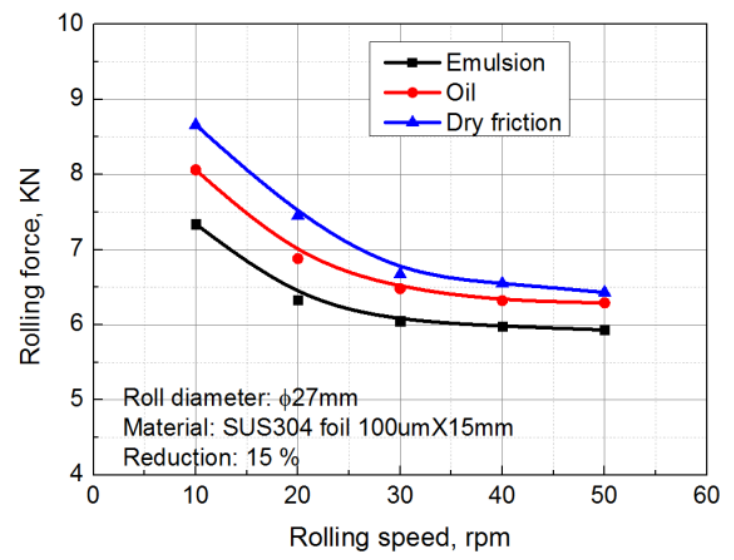

Fig. 8 Effect of lubricating condition on rolling force under various rolling speeds

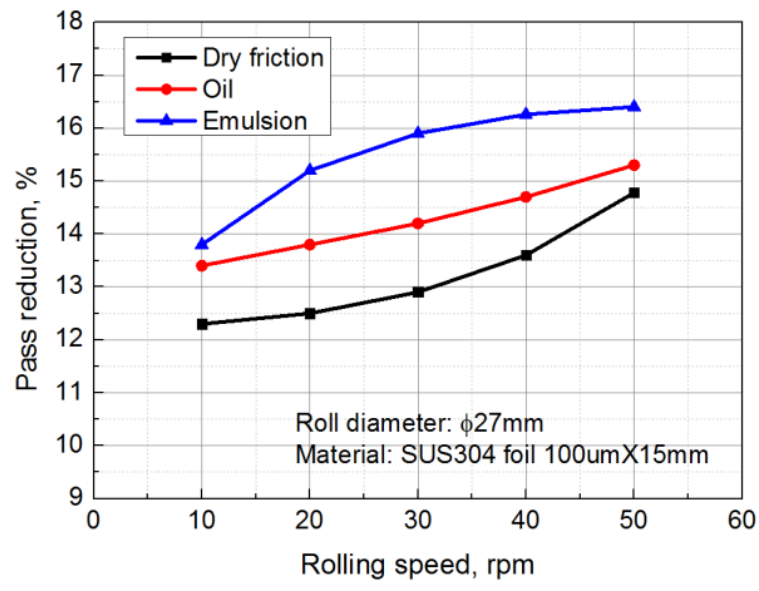

Fig. 9 Effects of rolling speed and lubricating condition on limit pass reduction.

The effects of rolling speed and lubricating condition on limit pass reduction are shown in Fig. 9. It can be seen that the pass reduction is sensitively increased with increasing rolling speed under the constant rolling force without roll gap adjustment. The hydrodynamic lubrication becomes gradually predominant with the rolling speed and the friction is reduced accordingly. When using an oil or emulsion, the limit pass reduction is larger than that in dry friction rolling. Under high rolling speed, the limit pass reduction vibration is higher for dry friction while it is insensitive for emulsion lubrication. The low friction reduces the rolling force, which then reduces the elastic flattening of work rolls and enables a larger limit reduction.

\subsection{Surface topography analysis after micro rolling}

The surface roughness has a large effect on the film thickness and its effect is especially important. With low viscosity-liquids, the foil and the roll surface roughness are much larger than film thickness in the hydrodynamic emulsion, and surface roughness must have a substantial effect on lubrication film thickness. Since the roll is much harder than the foil, the foil's asperities are expected to change shortly after roll biting. As a laboratory desk-top rolling mill, where the volume of the rolled metal is much less, the roll's surface roughness is not expected to change significantly, and the change can be neglected. Fig. 10 illustrates the rolled foil surface roughness variation with rolling lubricating conditions. Rolling trace and surface valley are significantly indicated in the surface topography. In the case without of lubricant, the roll surface is unevenly coated with foil, while in emulsion rolling there exists homogenious coating with foil. The unevenly coated roll has rougher 
surface. In addition, the lubricating condition is remarkably affected by the roll surface because the forward slip in foil rolling is larger than that in strip rolling. It can be seen that the wavelength of surface roughness in friction rolling condition is larger than that in emulsion or oil rolling from Fig. 10. The structure consists of parallel grooves perpendicular to the rolling direction. By the theory of Wilson [12], those grooves are formed by the differential deformation of the grains and should present a small depth, and consequently a small surface roughness.

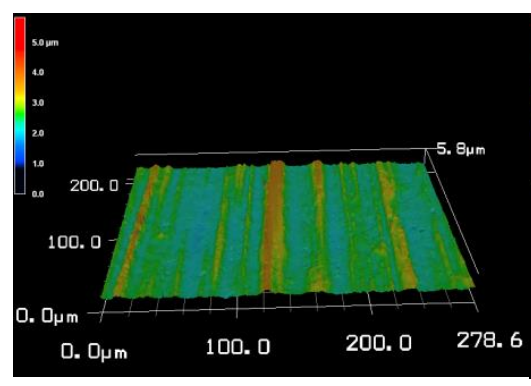

(a) Dry friction

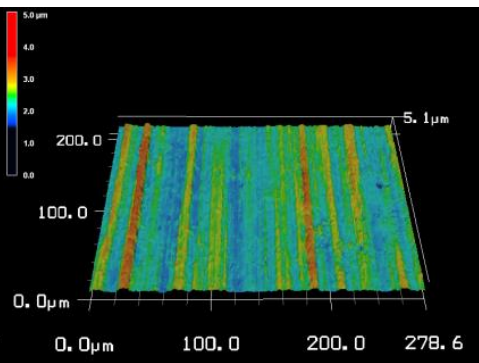

(b) Oil lubrication

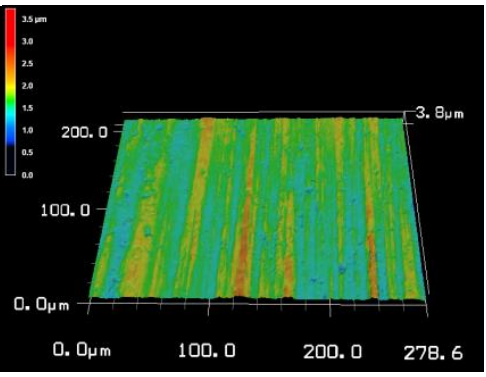

(c) Emulsion lubrication

Fig. 10 Rolled foil surface roughness under three different lubricating conditions.

Fig. 11 shows the AFM micrograph of rolled foil with and without lubricating during rolling. It can be seen that more flat areas are found in the surface of the rolled foil in lubricating rolling. Also the much rougher surface is located on the rolled foil surface in the Fig. 10 (a) of dry rolling.

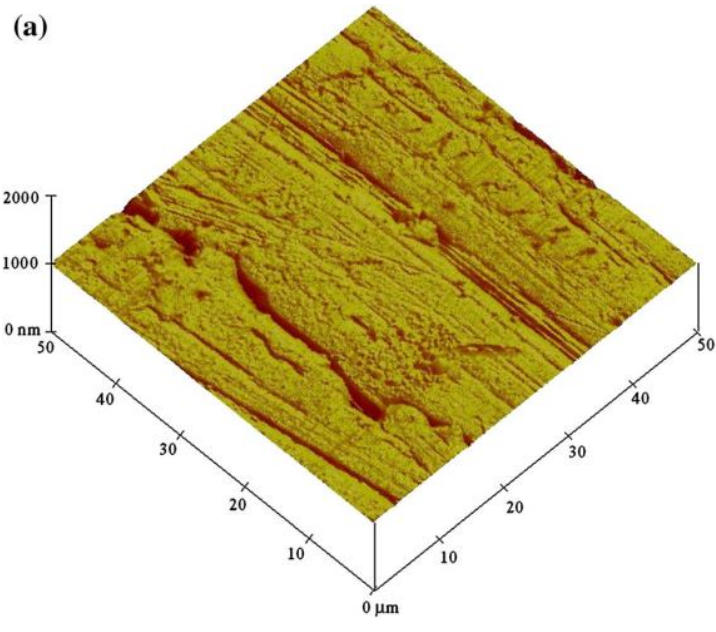

(a) dry rolling

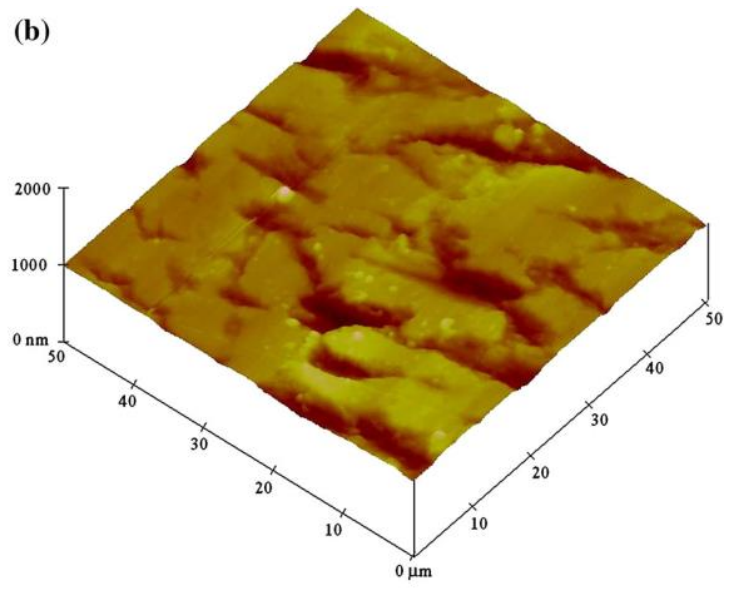

(b) oil lubrication rolling

Fig. 11 AFM micrograph of rolled foil with and without lubricating rolling

Details of the surface roughness topography may influence the behaviour of the foil during rolling. In addition, this topography plays important role in the tribological behaviour in the roll bite. The effect of wavelength of roughness has been explored using measurements of the surface spectrum on strip rolled in the mixed lubrication regime on an experimental mill [11]. Friction and the surface quality of the rolled foil are closely related to the amount of oil drawn into the bite and the surface roughness on the rolls and the in-going foil.
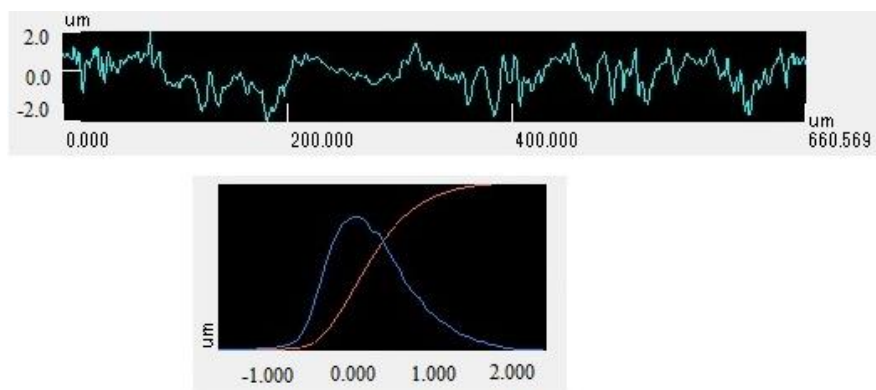

(a) Roughness distribution along the foil surface 


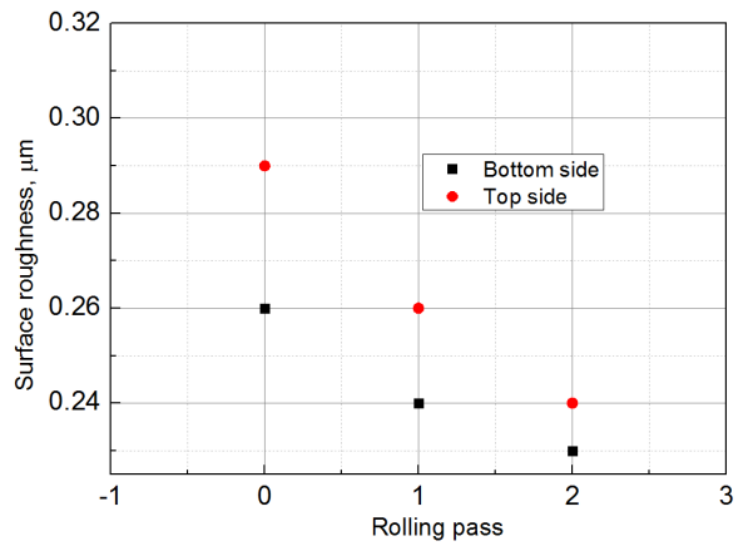

(b) Roughness change with rolling pass

Fig. 12 Surface roughness evolution during rolling process

Fig.12 (a) shows the surface roughness distribution along the rolled foil surface. The surface roughness of the initial foil and rolled foil samples taken after the first and second passes is shown in Fig. 12 (b). Each point represents an average of 20 measurements. Results show that the roughness on the bottom surface of the initial foil is significantly greater than on the top surface. Nevertheless, both sides of the surface have nearly conformed to the roll surface after the first pass, so that the difference between the two sides is then reduced. In the second pass, the surface roughness is further reduced slightly.

The surface quality continuously changes in rolling process, and the surface quality is of great difference with different oil film thickness. Bacause there is a thin layer of oil film thickness in rolling deformation zone, which not only prevent the adhesion between roller and sample surfaces but also make sample surface fully crushed, so, the rolled surface is bright and the surface quality is improved.

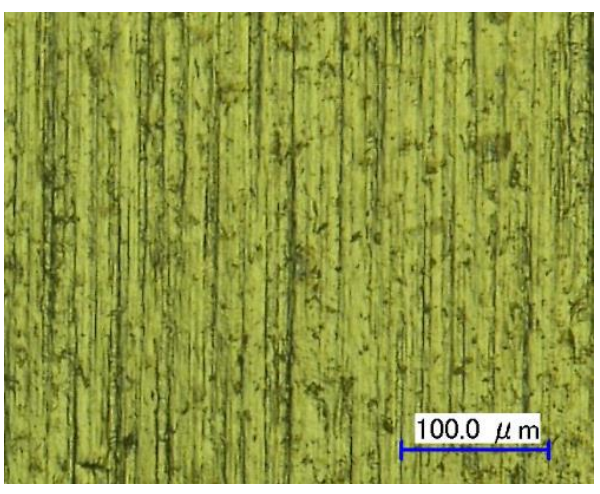

(a) $15 \mathrm{rpm}$ in rolling speed

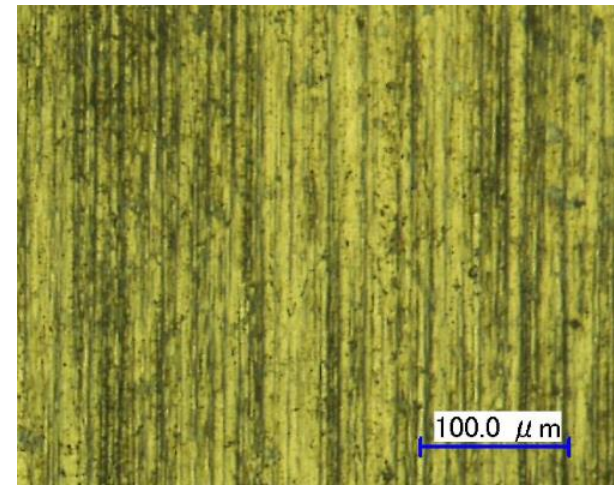

(c) 40rpm in rolling speed

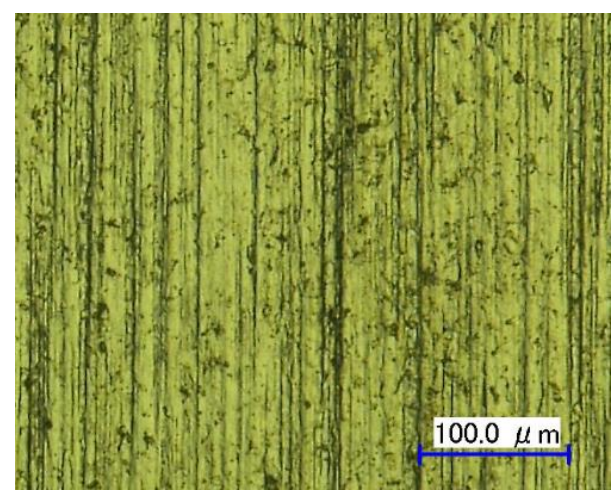

(b) 30rpm in rolling speed

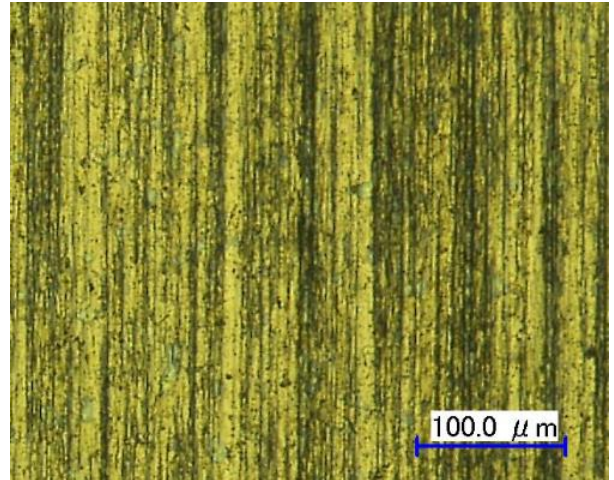

(d) 50rpm in rolling speed

Fig. 13 Effects of rolling speed on oil pit distribution under oil lubricating rolling (reduction 15\%).

Micro pits play an important role in the surface finish of stainless steel, understanding of their evolution during forming processes is very limited. Fig. 13 illustrates the effects of rolling speed on oil pit distribution under oil lubricating rolling, it can be seen that more oil pits appeared in foil surface with increasing rolling speeds. In other word, a lot of oil pits are formed in high speed rolling and make the dull surface. It seems that 
the pits observed on the foil surface are associated with surface roughening in regions where there is a significant oil film separating the roll and the foil. Under low rolling speed zone, the speed effect on oil pit is insignificant, but there is a great difference in high rolling speed zone.

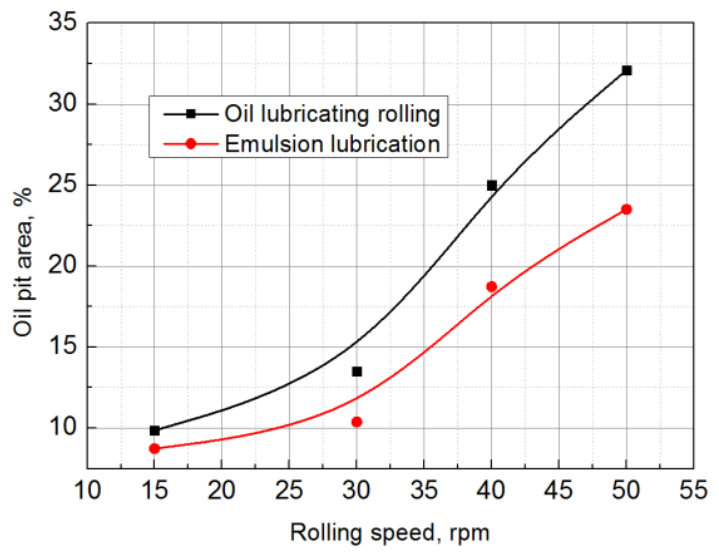

Fig. 14 Oil pit area with rolling speed

Fig. 14 shows the oil pit area change with rolling speed. It can be seen that the oil pit area increases with the increasing rolling speed. The rolling speed effect is more significant in oil lubricating rolling than that in emulsion lubricating rolling under high rolling speed zone.

\section{Conclusions}

The micro rolling deformation characterisation has been investigated successfully in micro rolling mill. Tribological size effect is also observed for different foil thickness of $100 \mu \mathrm{m}$ and $50 \mu \mathrm{m}$. The oil film thickness is higher in the thicker foil than that in thinner foil. The oil film thickness decreases with increasing pass reduction and decreasing rolling speed. The lubricant conditions influence the surface roughness evolution during rolling. In relation to increase in oil film thickness, rolling pressure is reduced, in contrast, the product surface becomes dull. The most preferable lubricant for foil rolling is emulsion, and rolling force decreases dramatically in lubricating rolling. Lubricating condition is remarkably influenced by roll coating formation, especially in using the smooth surface of rolls. The amount of micro oil pits increases with rolling speed. These findings will provide useful information for micro rolling of ultra-thin foil.

\section{Acknowledgements}

The authors would like to give thanks to Prof. Yoshino of Tokyo Institute of Technology and Prof. Koyama of Chiba University in rebuilding of micro rolling mill. The first author is grateful to the Japan Society for Promotion of Science (JSPS), Japan for awarding of JSPS fellowship (FY 2012-2014) to carry out research in Japan. This research was supported by the Grant-in-Aid for JSPS Fellows (Grant No. 24.02770).

\section{References}

[1] Le, H., Sutcliffe, M., 2006. A multi-scale model for friction in cold rolling of aluminium alloy, Tribology Letters, 22 (1), 95-104.

[2] Le, H., Sutcliffe, M., 2003. A friction model for cold strip rolling with two-wavelength surface roughness in the "mixed" lubrication regime, Transactions of the ASME, 125 (7), 670-677.

[3] Lenard, J., editor,2007. Primer on flat rolling, A monograph for those who need to understand the basic of the flat rolling process, Elsevier, 84 Theobald's Road, London WC1X8RR, UK.

[4] Fleek, N., Johnson, K.,1987. Towards a new theory of cold rolling thin foil, International Journal of Mechanical Science, 29 (7), 507524.

[5] N.A. Fleek, K.L. Johnson, M.E. Mear and L.C. Zhang, Cold rolling of foil, Porceedings of the Institution of Mechanical Engineers, 26 (1992) 119-131.

[6] Vollertsen, F., Hu, Z., 2009. Tribological size effects in sheet metal forming measured by strip drawing test, Ann. CIRP 55, $291-294$.

[7] Deng, J., Fu M., Chan, W., 2001. Size effect on material surface deformation behaviour in micro-forming process, 528 (13), $4799-4806$.

[8] Azushima, A., Noro, K., 1998. Analysis and quantitative consideration of inlet oil film thickness in cold sheet rolling with oil in wateremulsions, Journal - Japan Society for Technology of Plasticity, (39) 1238-1242.

[9] Sadowski, P., Stupkiewicz, S., 2010. Combined effect of friction and macroscopic deformation on asperity flattening, Tribology International, 43 (9), 1735-1741.

[10] Dick, K., Lenard, J., 2005. The effect of roll roughness and lubricant viscosity on the loads on the mill during cold rolling of steel strips, Journal of Materials Processing Technology, 168 (1), 16-24. 
[11] Batalha, G., Filho, M., 2001. Quantitative characterization of the surface topography of cold rolled sheets- new approaches and possibilities, Journal of Materials Processing Technology, 113 (5), 732-738.

[12] Wilson, W., Walowit, J., 1972. An isothermal hydrodynamic lubrication theory for strip rolling with front and back tension, in: Proceedings of the Tribology Convention, I. Mech. E. London, 169-172.

[13] Lugt, P., Wemekamp, A., Napel, W., Liempt, P., Otten, J., 1993. Lubrication in cold rolling: elasto-plasto-hydrodynamic lubrication of smooth surfaces, Wear, 166 (3), 203-214

[14] Atkins, A.G., 1974. Hydrodynamic lubrication in cold rolling, Intional Journal Mechanical Science, (16) 1-19.

[15] Kosasih, P.B., Tieu, A.K., 2007. Mixed film lubrication of strip rolling using O/W emulsions, Tribology International (40) 709-716.

[16] Parit, N., AND Cheng, H.S., An average flow model for determining eggects of three-dimensinal roughness on parial hydrodynamic lubrication, ASME Journal of Lubrication Technology, 100 (1978) 12-17.

[17] H.R. Le, M.P.F. Sutcliffe, Analysis of surface roughness of cold-rolled aluninium foil, Wear (2000) 71-78.

[18] M.P.F. Sutcliffe, P. Montmitonnet, Numerical modelling of lubricated foil rolling, La Revue de Metallurgie-CIT/Sciecnce et Genie des Materiaux, (2001) 435-442.

[19] Chang D.F., Marsault N., Wilson W.R.D., Lubrication of strip rolling in the low-speed mixed regime, Tribology Transactions, 39 (1996) 407-415. 